\title{
Teaching pharmacotherapeutics to pharmacy students at a Nigerian university: Student perspectives
}

\author{
S N Abdu-Aguye, ${ }^{1}$ MClinPharm; H Yusuf, ${ }^{2}$ MSc Clin Pharm; H U Maaji, ${ }^{1}$ MPharm; H M Rabiu, ${ }^{1}$ BPharm \\ ${ }^{1}$ Department of Clinical Pharmacy and Pharmacy Practice, Faculty of Pharmaceutical Sciences, Ahmadu Bello University, Zaria, Nigeria \\ ${ }^{2}$ Department of Clinical Pharmacy and Pharmacy Administration, Faculty of Pharmacy, University of Maiduguri, Borno, Nigeria
}

Corresponding author: S N Abdu-Aguye (sn.abduaguye@gmail.com)

\begin{abstract}
Background. Pharmacotherapeutics is an essential component of undergraduate pharmacy curricula worldwide. Therefore, improving the content and teaching of pharmacotherapeutic courses will better equip young pharmacists for their future careers.

Objectives. To assess the perception and views of fourth- and fifth-year pharmacy students at Ahmadu Bello University, Zaria, Nigeria, on the content and structure, as well as methods of lecture delivery of a pharmacotherapeutics course.

Methods. This was a sequential mixed-methods study. During the first phase, a pretested questionnaire containing both open- and closed-ended questions was distributed to all 201 students who enrolled for the course during the 2015/2016 academic session. After analyses of questionnaire responses, two focus group discussions (FGDs) were held with 16 randomly selected students (8 participants per group).

Results. Over half of respondents (54\%) had enrolled for the course more than once. Analyses of qualitative data from both questionnaires and FGDs yielded three themes: poor student awareness, relevance, and shortcomings in course structure and delivery. The most common complaints of students revolved around the bulkiness of the course and non-interactive teaching methods used by course lecturers. Their enjoyment of certain parts of the course was linked to a perceived relevance of some disease conditions over others.

Conclusion. There is a need to improve the course structure and teaching of pharmacotherapeutics at the institution, as well as student participation in their own learning.
\end{abstract}

Afr J Health Professions Educ 2018;10(4):235-237. DOI:10.7196/AJHPE.2018.v1014.1092

Pharmacotherapeutics as defined by the Merriam-Webster Medical Dictionary is 'the study of the therapeutic uses and effects of drugs in disease states. ${ }^{[1]}$ It is an essential component of the undergraduate pharmacy curriculum worldwide, and often encompasses drug therapy and several other aspects of patient care. With the move towards greater pharmacist involvement in patient care, the new-generation pharmacist needs to have an above-average clinical knowledge of various medications and disease states. $^{[2]}$

The Doctor of Pharmacy (PharmD) degree was recently approved as the minimum requirement for registration as a pharmacist in Nigeria. Therefore, evaluating student perceptions of teaching methods and course content within the previous Bachelor of Pharmacy (BPharm) curriculum would help us to develop an improved pharmacy education experience for future students. This article describes a project aimed at exploring the perceptions and views of undergraduate pharmacy students at Ahmadu Bello University, Zaria, Nigeria, on the course content and structure, as well as methods of delivery of a pharmacotherapeutic course.

\section{Methods \\ Setting}

The study was conducted among fourth- and fifth-year undergraduate students, Faculty of Pharmaceutical Sciences, Ahmadu Bello University. Ethical approval (ref. no. ABUCUHSR/2016/UG/004) and permission to perform the study were obtained from the Research Ethics Committee of the University. Pharmacotherapeutics 1 (PHCP 403) is a fourth-year 3 -credit unit course (45 contact hours) taught during the first semester of every academic session by permanent academic staff of the Department of Clinical Pharmacy and Pharmacy Practice. The major objective of the course is to educate students on the pharmacotherapeutic management of common diseases that affect the cardiovascular, respiratory, renal and haematological systems and to provide an overview of nutritional disorders. The course has several prerequisite modules, including anatomy, physiology, pharmacology and pathology, and students are required to pass information technology before enrolling in the final-year course of pharmacy clinical ward rounds.

\section{Study design}

A sequential mixed-methods approach was used to collect data in two phases - from April to August 2016. During the first phase, a pretested anonymous questionnaire containing open- and closed-ended questions was distributed to all 201 students who enrolled for the course at the end of the 2015/2016 academic session. The questionnaire contained three sections: part 1 collected general demographic information on the student population, including estimated attendance at lectures and student perceptions of whether course objectives had been fulfilled; part 2 contained 9 statements that were used to evaluate course delivery (using a Likert scale) by each of the 5 lecturers who taught the course; and part 3 comprised 3 open-ended questions that explored the most enjoyable parts and difficulties encountered, as well as ideas on how best to improve the course. After analysis of student responses to the open-ended questions in the first phase, two focus group discussions (FGDs), each lasting $\sim 1$ hour, were audio-recorded with 16 randomly selected students ( 8 participants per focus group). The purpose of these FGDs was to aid better understanding 
of the qualitative data generated from the questionnaires; therefore, the questions asked were formulated from questionnaire responses. Selection of participants and moderation of the FGDs were carried out by a lecturer from another university to ensure that students could express themselves freely without any fear of victimisation. FGD participants all signed informed consent forms.

\section{Data analysis}

Data collected from the closed-ended questions in the survey instrument were coded and entered into Microsoft Excel 2013 (Microsoft Corp., USA) to generate descriptive statistics. Data from the open-ended questions and transcribed FGDs were analysed using qualitative content analysis. Relevant statements were identified from student responses and grouped together based on similarities to generate themes. Two of the main investigators performed the thematic analyses; the themes were verified by a third researcher. Representative quotes were used to highlight pertinent statements.

\section{Results}

Of the 201 questionnaires administered, 190 responses were obtained, giving a $94.5 \%$ response rate. Background characteristics of study respondents are described in Table 1.

Over half of the surveyed respondents had enrolled for the course at least once before. Ninety-three percent claimed to have attended at least half of the lectures for the course, while only $11.3 \%$ admitted to ever seeking further clarification from a course lecturer.

\section{Students' perceptions of lecturers' teaching style}

Fig. 1 represents study participants' responses (using a Likert scale) towards the statement, 'Lecturer X encouraged student participation during his/her lectures'. On average, just more than half of respondents agreed that all course lecturers encouraged student participation during their lectures. However, this statement had a notable neutral category, with between $16 \%$ and $\sim 25 \%$ of responses for all 5 lecturers falling into this category.

\section{Qualitative data}

\section{Theme 1: Poor student awareness}

Students appeared to be poorly aware regarding several topics, from their initial motivation for studying pharmacy, to how to answer test/

Table 1. Respondents' background information, lecture attendance and engagement with course lecturers

\begin{tabular}{lll}
\hline & Variable & $\boldsymbol{n}(\%)$ \\
\hline Attempted course & 1 & $87(45.8)$ \\
& 2 & $69(36.3)$ \\
Estimate of attendance at lectures & $\geq 3$ & $34(17.9)$ \\
& $<50$ & $13(6.8)$ \\
& $50-75$ & $62(32.6)$ \\
'Did you ever meet any of the course lecturers for further clarification on & $>75$ & $115(60.6)$ \\
any aspect of the course outside the classroom?' & No & $21^{*}(11.3)$ \\
'Values in this cell do not total 190 because of missing responses. & & $166(88.7)$
\end{tabular}

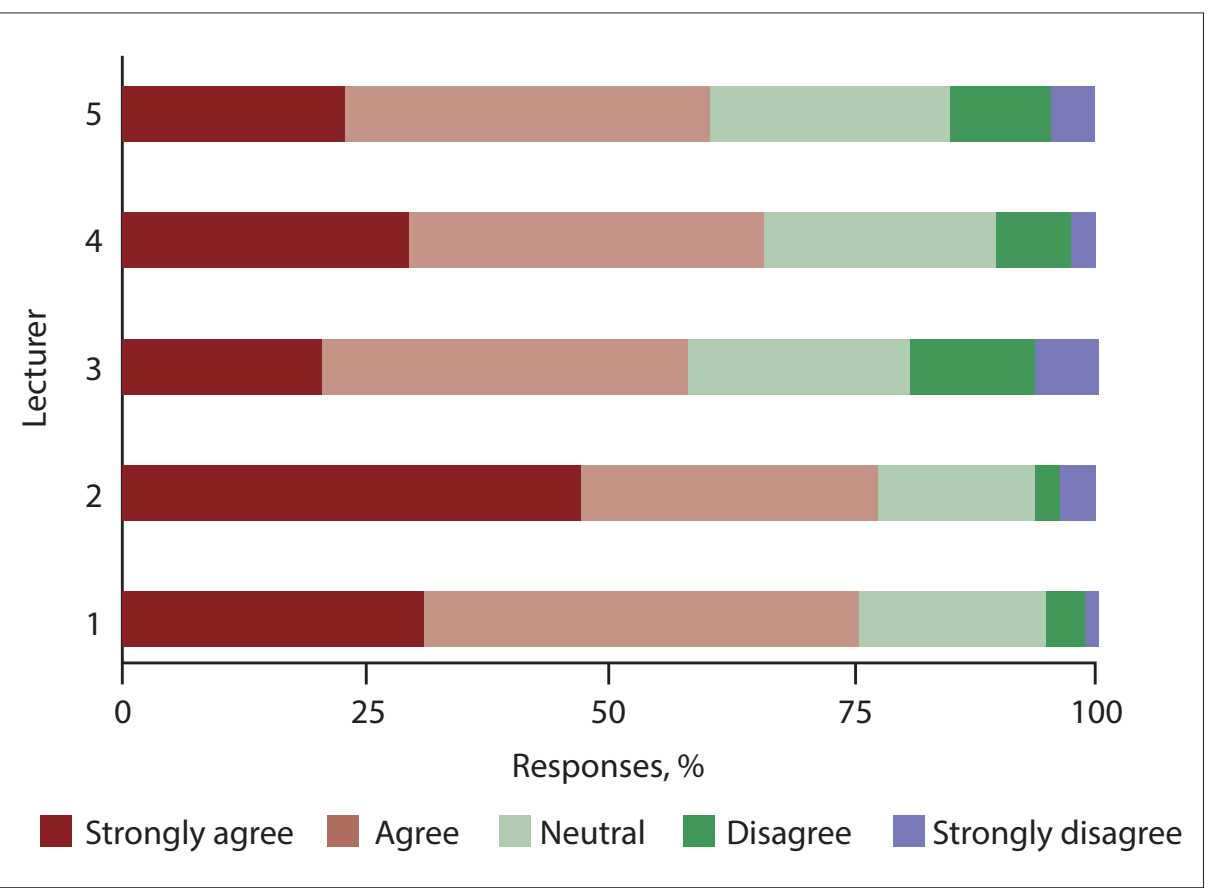

Fig. 1. Responses to the statement 'Lecturer X encouraged student participation during his/her lectures'.

examination questions, which seemed to be the main focus of many of the respondents. Furthermore, a number of students did not seem to see themselves as stakeholders/responsible for their learning, instead believing that their learning was the sole responsibility of lecturers and other external factors:

'... like me, I always sit at the back. Sometimes they will just be discussing, you can't hear from the back. Actually, I don't like sitting in front. But if they [the lecturers] increase their confidence, then they will be audible enough.' (Fifth-year student)

\section{Theme 2: Relevance}

All students agreed that the course was important and that lower-level prerequisite courses were needed if a clear understanding of the course was to be obtained; however, some of them felt that the prerequisite course content could be streamlined to better equip students with a good foundation for PHCP 403:

'All these courses, physiology, anatomy and pathology, are relevant, but we are not studying them appropriately, that is why even in this PHCP 403 we are having lapses.' (Fifth-year student)

Their enjoyment of certain sections of the course was linked to their perceived relevance of some disease conditions over others:

'Cardiovascular diseases (CVDs) are very common in our normal lives because of the high prevalence of CVDs within our society. Thus, it is easier to comprehend CVD topics than other diseases because you will be constantly hearing things about the diseases and the risk factors.' (Fourth-year student) 


\section{Theme 3: Shortcomings in course content and delivery}

Most students stated that the major problem with the course was its 'bulkiness', which, together with inadequate time to study (because of other courses), led to confusion - a major cause of student failure. Another complaint was the absence of a 'practical aspect', making it very easy to forget material learnt in class. However, opinions varied on the nature that this 'practical aspect' should take. Some felt that clinical ward rotations would be helpful, while others suggested that linking classroom lectures with real-life scenarios would be beneficial.

While most students reported that the course lecturers were generally good teachers, several still felt that there was room for improvement. Perceptions of lecturer-student relationships, however, were particularly poor, with several students complaining about poor approachability or excessive strictness of the course lecturers:

'Some lecturers when they enter class they behave "no nonsense" ... Normally for good communication between students and lecturers there should be interaction, like asking questions so that the students would be carried along. However, if a lecturer behaves "no nonsense", I can have questions to ask in class but I will reserve them ... ? (Fourth-year student)

\section{Discussion}

This was the first study in our faculty at Ahmadu Bello University, and possibly in pharmacy schools in Nigeria, which attempted to obtain feedback from students to improve the quality of the learning process. Pharmacotherapeutics is a particularly focal course in the undergraduate pharmacy curriculum, and special attention needs to be paid to improve the quality of its teaching.

The abovementioned prerequisite modules to this course include anatomy, physiology, biochemistry and pathology, all of which are offered during the second and third undergraduate years. These courses are given in other faculties, offered simultaneously to students of these faculties, and are taught by external lecturers who often do not fully understand the specific needs of our students.
This can lead to student dissatisfaction with course content, high failure rates and a loss of actual benefit from this learning, as suggested from the results of this study. Postma and Bronkhorst ${ }^{[3]}$ reported a similar level of dissatisfaction on the part of dental students sharing basic science courses with medical students at a South African (SA) university.

Learning requires active involvement of students and lecturers. Both groups are important stakeholders - students in influencing the teaching environment for lecturers, and lecturers in the learning process for students. ${ }^{[4]}$ However, educational experiences are often only as effective as students' engagement with them ${ }^{[5]}$ Consequently, understanding the thought processes of students is very important if academics are to optimise student learning experiences. Several students in our study seemed to view learning as an event that 'happened' to them, rather than one that requires active participation. This finding was in contrast to Roman et al.'s ${ }^{[4]}$ study, who discovered that, on average, third-year students in the Faculty of Health Sciences at an SA university perceived themselves to be agents of their own learning. Further work needs to done in this area, especially within the Nigerian setting, to assess (and change if necessary) the level of preparedness of students entering higher-education institutions.

While students generally perceived teaching by course lecturers to be adequate, a recurring complaint was with regard to the non-interactive nature of the teaching methods employed. Important to consider is the changing nature of students over the years. As Oblinger ${ }^{[6]}$ stated, 'The aging infrastructure and the lecture tradition of colleges and universities may not meet the expectations of the new generation of students raised on the Internet and interactive games'. While our lecturers definitely need to improve their classroom demeanour and communication with students, adopting relatively new teaching techniques may also be useful. Studies have shown benefits in using techniques such as problem-based learning and educational games in teaching pharmacotherapeutics, ${ }^{[7-9]}$ although these methods may not be suitable for all topics. Other methods (e.g. team-based learning) shift some of the onus of learning onto the students, ${ }^{[10,11]}$ and are thus doubly advantageous.

\section{Conclusion}

There is a definite need to improve on the course structure and content, as well as methods used in teaching the course at our institution. These results will be used to comprehensively modify several parts of the course and improve student participation in the learning process.

\section{Declaration. None.}

Acknowledgements. The authors acknowledge the support of the Department of Clinical Pharmacy and Pharmacy Practice, Ahmadu Bello University, Zaria, Nigeria, for providing the materials to print the questionnaires used in this work.

Author contributions. SNA-A and HY designed the study, participated in data collection, and analysed and drafted the article. HMR collected the data and HUM analysed the data and reviewed and approved the final draft of the article.

Funding. None.

Conflicts of interest. None.

1. Merriam-Webster Medical Dictionary - Pharmacotherapeutics. 2017. https://www.merriam-webster.com/medical/pharmacotherapeutics (accessed 24 July 2017).

2. Werlissandra M de S, Alessandra RM, Angelo RA, Divaldo P de LJ Wellington $B$ da $S$. Teaching in pharmaceutical care: A systematic review. Afr J Pharm Pharmacol 2015:9(10):333-346. https://doi. org/10.5897/ajpp2014.4181

3. Postma TC, Bronkhorst L. Second-year dental students' perceptions about a joint basic science curriculum. Afr J Health Professions Educ 2015;7(2):199-201. https://doi.org/10.7196/ajhpe.409

Roman NV, Titus S, Dison A. Relationship between student preparedness, learning experiences and agency: Perspectives from South African university. Afr J Health Professions Educ 2016;8(1):30-32. (1)

5. Richards J, Sweet L, Billett S. Preparing medical students as agentic learners through enhancing student engagement in clinical education. Asia-Pacific J Coop Educ 2013;14(4):251-263.

6. Oblinger D. Gen-Xers and millennials: Understanding the new students. EDUCAUSE Review 2003;38(1):44.

. Toklu HZ. Problem based pharmacotherapy teaching for pharmac students and pharmacists. Curr Drug Deliv 2013;10(1):67-70. https:// doi.org/10.2174/1567201811310010012

8. Cheng JWM, Alafris A, Kirschenbaum HL, Kalis MM, Brown ME Problem-based learning versus traditional lecturing in pharmacy student short-term examination performance. Pharm Educ 2003;3(2):117-125. https://doi.org/10.1080/156022103100015128

9. Barclay SM, Jeffres MN, Bhakta R. Educational card games to teach pharmacotherapeutics in an advanced pharmacy practice experience. Am J Pharm Educ 2011;75(2):33. https://doi.org/10.5688/ajpe75233 Am J A S Bopovich NG. A student-initioted integrated pe 233 . Hopman S, Popovich NG. A student-initiated, integrated pharm

11. Johnson JF, Bell E, Bottenberg M, et al. A multiyear analysis of teambased learning in a pharmacotherapeutics course. Am J Pharm Educ 2015;78(7):142. https://doi.org/10.5688/ajpe787142

Accepted 24 April 2018 